\title{
The impact of fire on terrestrial tardigrade biodiversity: a first case-study from Portugal
}

\author{
Filipe VICENTE, ${ }^{1 *}$ Michele CESARI,${ }^{2}$ Artur SERRANO,${ }^{1}$ Roberto BERTOLANI ${ }^{3}$ \\ ${ }^{1}$ Centro de Biologia Ambiental e Departamento de Biologia Animal, Faculdade de Ciências da Universidade de Lisboa, Campo Grande \\ C2, 1749-016 Lisboa, Portugal; ${ }^{2}$ Dipartimento di Scienze della Vita, Università di Modena e Reggio Emilia, Via G. Campi 213/D, \\ 41125 Modena; ${ }^{3}$ Dipartimento di Educazione e Scienze Umane, Università di Modena e Reggio Emilia, Via A. Allegri 9, \\ 42121 Reggio Emilia, Italy \\ *Corresponding author: fjvicente@fc.ul.pt
}

\begin{abstract}
Currently, loss of habitat is the greatest threat to biodiversity, yet little is known about its effect on microscopic animal taxa, such as Tardigrada. One of the causes of habitat destruction is forest fire, both natural and anthropogenic. The latter is commonly used in agriculture to kill insect pests, as a soil preparation, or conservation to create habitat mosaics. In Portugal, 42\% of fire frequency is anthropogenic. There is no consensus on the impact of fires on biodiversity, with studies pointing towards different conclusions. Different methods and target taxonomic study groups may partly explain this paradigm. This study is the first into possible effects of habitat destruction on tardigrade populations, in which we analysed the taxonomic and genetic variations of tardigrades from a fire affected location in a Portuguese natural park. Sampling was performed over a 10-year period, from 2000 to 2010. The location was affected by a small fire in 1998 and a big fire in 2003. A total of 11 species from nine separate genera was recorded, from which 19 cox1 haplotypes were identified. Our data suggest a negative effect of a forest fire on tardigrade populations. Taxonomic and genetic richness, as well as abundance show lower levels in the years after a fire, compared with the preceding years. Additionally, the population recovered visibly faster after the small fire than after the bigger one. This is consistent with larger fires destroying larger forest areas, leaving fewer animals at a farther distance available for re-colonisation. Most species found before the main fire are also found after it, indicating these tardigrades have a high recolonisation capability. However, only three of all recorded haplotypes were found both pre and post the main fire, which indicates genetic diversity loss as a direct consequence of fire. Therefore, we conclude that habitat destruction by means of forest fire has a detrimental effect on tardigrade biodiversity, and may have similar effects on other small animals.
\end{abstract}

Key words: fire impact, Tardigrada, cox1, Portugal, biodiversity, re-colonisation.

\section{INTRODUCTION}

Loss of habitat is currently the single greatest threat to biodiversity (Millennium Ecosystem Assessment, 2005). However, for many taxonomic groups there is still little or no evidence of habitat loss affecting intrinsic biodiversity and/or population structure (Andersen and Müller, 2000; Vicente, 2010). One such group is the phylum Tardigrada. These are microscopic metazoans that inhabit most terrestrial, freshwater and marine environments. In terrestrial environments, they are commonly found in aquatic microcosms, including mosses and lichens, where water films or microwater bodies are unpredictably added and temporarily retained.

In temperate climates, these micro-habitats are usually inactive during the warmer months because of desiccation, and in winter when frozen. Mosses and lichens recover their activity with the return of moisture, together with the usually anhydrobiotic fauna that usually inhabits them: tardigrades, rotifers and nematodes. During these periods of inactivity, these terrestrial micro habitats are particularly exposed to environmental threats such as forest fires.
Apart from the obvious directly destructive effect that fires have on biodiversity, their impact on ecosystems is very important, e.g., via the destruction of riparian flora supporting freshwater systems (New et al., 2010), by destroying soil grass and thus accelerating soil erosion (Naveh, 1998), or altering mammalian foraging behaviour (Wallace and Crosthwaite, 2005). Fires are known to reduce macrofaunal populations, and have historically been used to attack populations of agricultural damaging insects via direct kill or indirect habitat destruction (McCullough et al., 1998). Other common reasons behind the use of deliberate fires are the preparation of land for agriculture (Sim-Sim et al., 2004), or the reduction of organic fuel levels, to minimize the impact of high magnitude fires (Andrew et al., 2000; York, 2000). According to Simorangkir (2007) the biggest reason behind the widespread use of fire for land clearing is its low economic cost, mainly in large areas. For small forest areas, zeroburning alternatives can be as cost-effective as burning. The extent of fire induced damages is dependent on several factors, such as its type and intensity, environmental variables or organism adaptation to water loss (Araújo and 
Ribeiro, 2005). Global warming also exacerbates fire frequency. In Portugal, anthropogenic activities explain $42 \%$ of fire frequency and temperature anomalies $43 \%$ of the area burnt (Costa et al., 2011).

Nevertheless, there is no consensus on the effect of fire on biodiversity. Some studies suggest positive fire consequences, such as the maintenance of habitat mosaics at different succession stages (Gandhi et al., 2001). That is, according to Parr and Andersen (2006), an increasingly popular theory amongst conservation management agencies worldwide, which has resulted in patch mosaic burning being a commonly used biodiversity conservation strategy. However, other studies suggest a negative outcome, by destroying endemic and low dispersing species (Yanovsky and Kiselev, 1996; Quartau, 2009). This apparent incongruence could result from the different conditions in which individual studies were conducted, such as the fire regimes, the pre- and post-fire ecology of the region, or the focal taxa (Moretti et al., 2004; Parr and Andersen, 2006). According to New et al. (2010), pre- and post-fire data from burning sites are common omissions.

To date no such studies exist with a specific focus on tardigrades or other micro-invertebrate groups. In a broad spectrum study, Malmström et al. (2009) found that, five years after a fire, tardigrade abundance had recovered to $52 \%$ of that in the unburned area.

We elucidate how limno-terrestrial tardigrade populations respond to habitat loss caused by forest fire. To do so, we analysed consecutive samples from one small geographic mountainous area in Portugal, focusing on both changes in population dynamics as well as on their respective levels of genetic diversity.

\section{METHODS}

Samples of the moss species Orthotrichum striatum Hedwig, 1801 were collected from trees at Carvalhal da Moita do Conqueiro, Serra da Estrela's Natural Park, Portugal, $1529 \mathrm{~m}$ asl, from an area of roughly $10 \mathrm{~m}^{2}$ (Fig. 1), and kept in paper bags. Single samples were collected in 2000, 2003, 2005, 2006, 2007 and 2010. A major fire occurred in 2003, ca. one month after sampling; and only a small fire was previously reported in 1998. Even though the sampling site was visited in 2004, no sample was col-

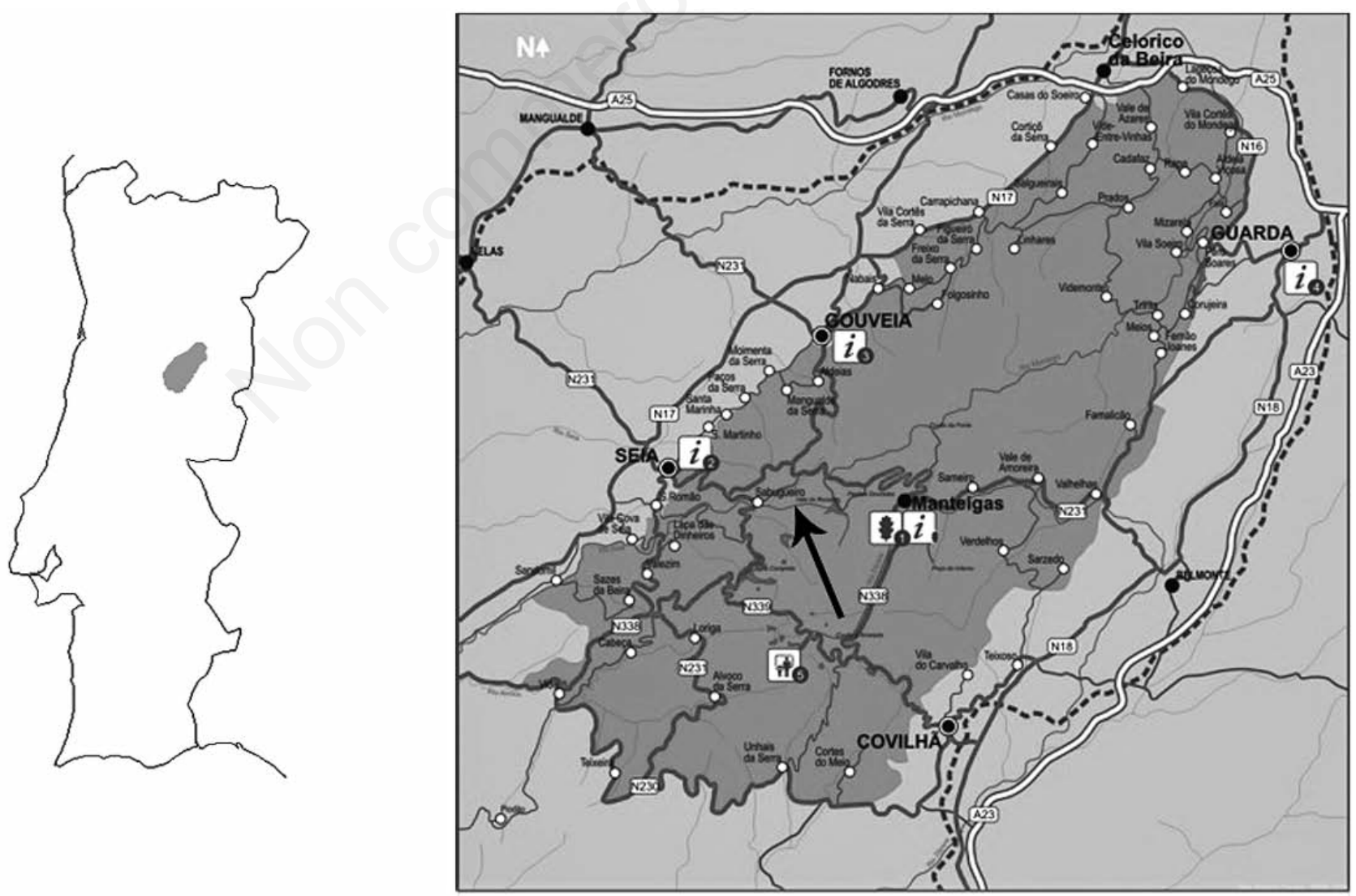

Fig. 1. Sampling site (Carvalhal da Moita do Conqueiro, Serra da Estrela, Portugal). General (left) and detailed (right) maps of Serra da Estrela's Natural Park. The arrow points to the sampling site. Source: www.icnf.pt (Instituto da Conservação da Natureza e das Florestas, 2007). 
lected then since new mosses were still getting established. Only a small sample per year was collected, in order to avoid significant alteration of the studied area.

Samples were left to air dry at room temperature, weighed and tested for animals by soaking for at least 30 min and washed through consecutive 500 and $38 \mu \mathrm{m}$ sieves. All animals and eggs present in a sieved sample were manually selected under a stereomicroscope. Since samples presented variant sizes, their dry weight was registered and each population's abundance was estimated as animal per gram of substrate (Fig. 2). Thus, tardigrade abundances from all years were made comparable.

Voucher specimens were photographed in vivo and then used for DNA analysis, following the protocol described in Cesari et al. (2011). The other animals and eggs were mounted on slides using Faure-Berlese fluid. In vivo and mounted specimens were observed using a Leitz DM RB light microscope, at $100 \times$ oil objective for the mounted specimens and eggs, at 40 or $100 \times$ oil objective for the in vivo specimens. Species richness (Margalef's test of richness, d), diversity (Shannon-Wiener index, H') and dominance (Simpson index, $\lambda$ ) have been calculated using Primer 5.2.9 (PRIMER-E Ltd., Lutton, UK), considering all animals found in the six years (Tab. 1). Statistical equality by t-Student tests of pairs of Shannon-Wiener indices of species diversity (Zar, 1996) was also computed (Tab. 2).

DNA extraction from single specimens and polymerase chain reaction (PCR) amplification of a fragment of the coxl gene were carried out following Cesari et al. (2009) protocol, using LCO-1490 (5'-GGT CAA CAA ATC ATA AAG ATA TTG G-3'; Folmer et al., 1994) and HCO-2198 (5'-TAA ACT TCA GGG TGA CCA AAA AAT CA-3'; Folmer et al., 1994) as primers. The ampli- fied products were gel purified using the Wizard Gel and PCR cleaning (Promega, Madison, WI, USA) kit. For assurance, both strands were sequenced using an ABI Prism 3100 sequencer (Applera, Norwalk, CT, USA). Sequences were translated to amino acids by using the invertebrate mitochondrial code implemented in MEGA version 5 (Tamura et al., 2011) in order to check for the presence of stop codons and therefore of pseudogenes. Nucleotide sequences were aligned with the Clustal algorithm implemented in MEGA5 (pairwise and multiple alignment parameters: Gap opening penalty: 15, Gap extension penalty: 6.66) and checked by visual inspection. Nucleotide sequences of the newly analysed specimens were submitted to GenBank (Accession Numbers JX683810JX683833). Specimens pertaining to Diploechiniscus oihonnae (Richters, 1903) (GenBank A.N. JX676191-4) were already analysed in Vicente et al. (2013) and they

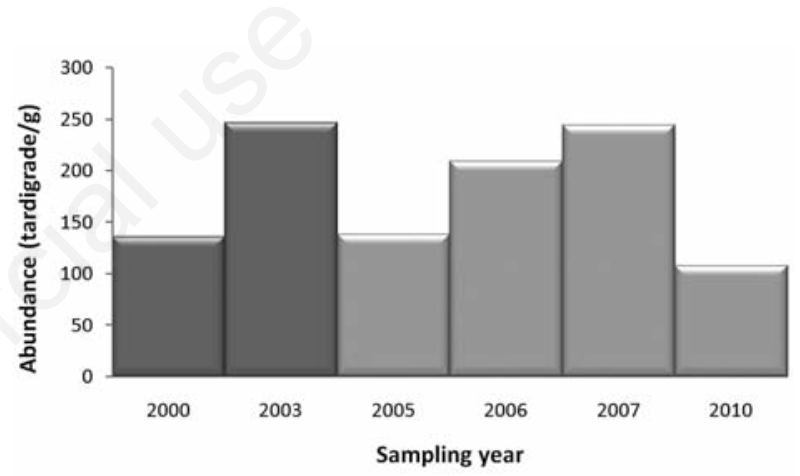

Fig. 2. Tardigrade abundances for each sampling year: before (dark-grey) and after (light-grey) the largest fire.

Tab. 1. Specimens and species abundances over the sampling years.

\begin{tabular}{|c|c|c|c|c|c|c|c|}
\hline \multirow[t]{2}{*}{ Species } & \multicolumn{7}{|c|}{ Number of specimens found } \\
\hline & 2000 & 2003 & 2005 & 2006 & 2007 & 2010 & Overall \\
\hline Macrobiotus cf. macrocalix & 1 & 15 & 8 & 46 & 2 & 8 & 80 \\
\hline Pseudechiniscus facettalis & 19 & 0 & 0 & 3 & 51 & 2 & 75 \\
\hline Echiniscus blumi & 0 & 0 & 0 & 0 & 0 & 61 & 61 \\
\hline Diploechiniscus oihonnae & 0 & 2 & 2 & 2 & 10 & 0 & 16 \\
\hline Milnesium cf. tardigradum & 1 & 5 & 5 & 2 & 0 & 2 & 15 \\
\hline Macrobiotus vladimiri & 3 & 1 & 1 & 4 & 0 & 1 & 10 \\
\hline Minibiotus furcatus & 0 & 6 & 0 & 0 & 3 & 0 & 9 \\
\hline Bryodelphax parvulus & 0 & 4 & 1 & 0 & 0 & 0 & 5 \\
\hline Hypsibius pallidus & 0 & 2 & 0 & 0 & 0 & 0 & 2 \\
\hline Ramazzottius cf. oberhaeuseri & 0 & 1 & 0 & 0 & 1 & 0 & 2 \\
\hline Echiniscus quadrispinosus & 1 & 0 & 0 & 0 & 0 & 0 & 1 \\
\hline Total specimens (n) & 25 & 36 & 17 & 57 & 67 & 74 & 276 \\
\hline $\mathrm{d}$ & 1.243 & 1.953 & 1.412 & 0.989 & 0.951 & 0.929 & \\
\hline$H^{\prime}\left(\log _{\mathrm{e}}\right)$ & 0.849 & 1.702 & 1.300 & 0.750 & 0.798 & 0.653 & \\
\hline$\lambda$ & 0.597 & 0.241 & 0.329 & 0.661 & 0.605 & 0.693 & \\
\hline
\end{tabular}

$d$, species richness; $H^{\prime}\left(\log _{e}\right)$, Shannon index for diversity; $\lambda$, Simpson index for dominance. 
were also included in the present analysis. Minimum spanning network analysis between haplotypes was performed by using Arlequin 3.1 (Excoffier et al., 2005) and visualized by using HapStar (Teacher and Griffiths, 2011). Haplotype diversity was estimated by using the program DnaSP v5 (Librado and Rozas, 2009). Sequencing success was estimated by dividing final sequence numbers by total extracted specimens, for each year.

\section{RESULTS}

A total of 276 animals (eggs were not considered) representing 11 species and nine genera were extracted from six samples, covering a 10 year time span. Sampling was not conducted in the unrepresented years. Abundances are depicted in Tab. 1, together with species richness (d), Shannon index (H') for diversity and Simpson index $(\lambda)$ for dominance in each sample (year).

Populations' abundances show similar lower scores in the years succeeding both smaller and larger fires (2000 and 2005). Abundances raised gradually with time passing by, from 2005 to 2006 and again to 2007, where population's abundance scores almost as high as 2003, the most abundant of all. In 2010, an unexpected decrease in abundance with respect to the previous sampling was observed.

Macrobiotus cf. macrocalix is the most commonly occurring species, the richest in specimen numbers and the only one present in all sampling years. These specimens differ from the type material of Macrobiotus macrocalix Bertolani and Rebecchi, 1993 by having a higher egg shell pit number and sometimes a crenulated distal disc of the egg processes, as well as for their different haplotype. Next, in terms of abundance, are Pseudechiniscus facettalis Petersen, 1951 and Echiniscus blumi Richters, 1903. In terms of continuity, M. cf. macrocalix is followed by Milnesium cf. tardigradum, Macrobiotus vladimiri Bertolani, Biserov, Rebecchi and Cesari, 2011 (both not found only in 2007), P. facettalis (not found in 2003 and 2005 ) and D. oihonnae (not found in 2000 and 2010). The remaining species are less abundant and present only in one (Hypsibius pallidus Thulin, 1911, Echiniscus quadrispinosus Richters, 1902, E. blumi) or two (Minibiotus furcatus Ehrenberg, 1859, Bryodelphax parvulus Thulin 1928, Ramazzottius cf. oberhaeuseri) of the six sampling years.

Species richness and diversity index (Shannon index $H^{\prime}$ ) both peaked in 2003, corresponding with the lowest dominance index (Simpson index $\lambda$ ), a few months before the largest fire (Tab. 1). Statistical equality of ShannonWiener index pairs evidences several significant differences (Tab. 2).

In regard to the molecular analysis, 19 coxl haplotypes were identified (Tab. 3) in all considered years. DNA has been extracted from specimens of every identified species but in some cases it was not possible to determine the haplotype. Tab. 3 also presents percentages of successful sequencing methods, shown by sampling year. Fig. 3 depicts a minimum spanning network for all scored haplotypes, their presence in each sample (year) and the intraspecific distances, in terms of substitutions.

The spanning network (Fig. 3) shows a reduced number of substitutions amongst most haplotypes, with the exception of $D$. oihonnae, where two haplotypes are separated by 22 substitutions. With four haplotypes each, Macrobiotus cf. macrocalix and D. oihonnae are the species with the highest genetic diversity. Milnesium cf. tardigradum follows with three haplotypes. Remaining species exhibit only one or two haplotypes. Macrobiotus cf. macrocalix also exhibits the only haplotype present in $100 \%$ of the species' samplings (haplotype A2).

\section{DISCUSSION}

Macrobiotus cf. macrocalix is the only species present in all sampling years. Morphological and genetic differences of these specimens from the type material and other populations of M. macrocalix will be discussed elsewhere (Bertolani et al., personal communication). Haplotype A2 of this species is present in every sample and is largely dominant with respect to the other three conspecific haplotypes.

The highest species richness and diversity index (Tab. 1) were reported for 2003, just a few months before

Tab. 2. Statistical equality of Shannon-Wiener index pairs. T-student values are under the diagonal, while degrees of freedom are indicated above the diagonal.

\begin{tabular}{lcccccc}
\hline $\mathrm{H}^{\prime}($ year $)$ & $0.849(2000)$ & $1.702(2003)$ & $1.300(2005)$ & $0.750(2006)$ & $0.798(2007)$ & $0.653(2010)$ \\
\hline $0.849(2000)$ & & 46 & 42 & 49 & 42 & 84 \\
$1.702(2003)$ & $3.235^{* *}$ & & 37 & 39 & 33 & 84 \\
$1.300(2005)$ & $1.551 \mathrm{~ns}$ & $1.671 \mathrm{~ns}$ & & & 117 & 119 \\
$0.750(2006)$ & $0.377 \mathrm{~ns}$ & $4.570^{* * *}$ & $2.278^{*}$ & & 140 \\
$0.798(2007)$ & $0.202 \mathrm{~ns}$ & $4.684^{* * *}$ & $2.196^{*}$ & $0.251 \mathrm{~ns}$ & \multirow{2}{*}{$0.826 \mathrm{~ns}$} \\
$0.653(2010)$ & $0.781 \mathrm{~ns}$ & $5.478^{* * *}$ & $2.847^{* *}$ & $0.501 \mathrm{~ns}$ & \\
\hline
\end{tabular}

ns, not significant $(P>0.05) .{ }^{*} 0.05 \geq P \leq 0.01 ;{ }^{* *} 0.01 \geq P \leq 0.001 ;{ }^{* * *} P<0.001$. 
Tab. 3. Number of sequenced specimens, distinct haplotypes (between parentheses) and haplotypes diversity $\left(\mathrm{H}_{\mathrm{d}}\right)$ registered in each year, for the different species.

\begin{tabular}{|c|c|c|c|c|c|c|}
\hline Species & 2000 & 2003 & 2005 & 2006 & 2007 & 2010 \\
\hline Macrobiotus cf. macrocalix & - & $3(\mathrm{~A} 1, \mathrm{~A} 2, \mathrm{~A} 3)$ & $2(\mathrm{~A} 2)$ & $2(\mathrm{~A} 2, \mathrm{~A} 4)$ & $1(\mathrm{~A} 2)$ & 1 (A2) \\
\hline Pseudechiniscus facettalis & - & - & - & 1 (B1) & 1 (B2) & - \\
\hline Echiniscus blumi & - & - & - & - & - & $2(\mathrm{C} 1, \mathrm{C} 2)$ \\
\hline Diploechiniscus oihonnae & - & 1 (D1) & 1 (D2) & 1 (D3) & 1 (D2) & - \\
\hline Milnesium cf. tardigradum & - & $1(\mathrm{E} 1)$ & $1(\mathrm{E} 2)$ & $2(\mathrm{E} 2, \mathrm{E} 3)$ & - & - \\
\hline Macrobiotus vladimiri & $1(\mathrm{~F} 1)$ & - & - & - & - & $1(\mathrm{~F} 1)$ \\
\hline Minibiotus furcatus & - & $1(\mathrm{G} 1)$ & - & - & $1(\mathrm{G} 2)$ & - \\
\hline Bryodelphax parvulus & - & $1(\mathrm{H} 1)$ & $1(\mathrm{H} 1)$ & - & - & - \\
\hline Hypsibius pallidus & - & - & - & - & - & - \\
\hline Ramazzottius cf. oberhaeuseri & - & - & - & - & - & - \\
\hline Echiniscus quadrispinosus & 1 (I1) & - & - & - & - & - \\
\hline Sequencing success $(\%)$ & 22.2 & 60.0 & 75.0 & 46.2 & 26.7 & 17.4 \\
\hline $\mathrm{H}_{\mathrm{d}}$ & 1.0 & 1.0 & 0.9 & 1.0 & 1.0 & 1.0 \\
\hline
\end{tabular}

-Species not registered in a given year, or DNA extracted but haplotypes not determined. Each species is assigned a unique haplotype letter tag.

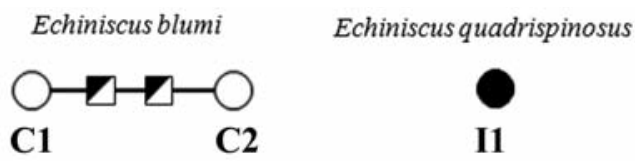

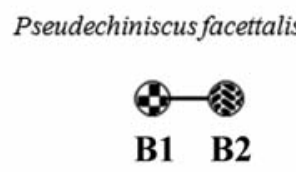

Bryodelphaxparvulus

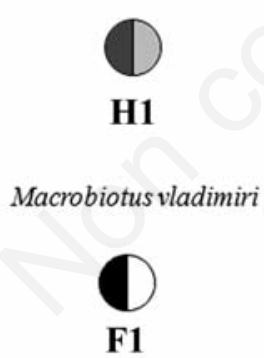

Milnesium cf. tardigradum
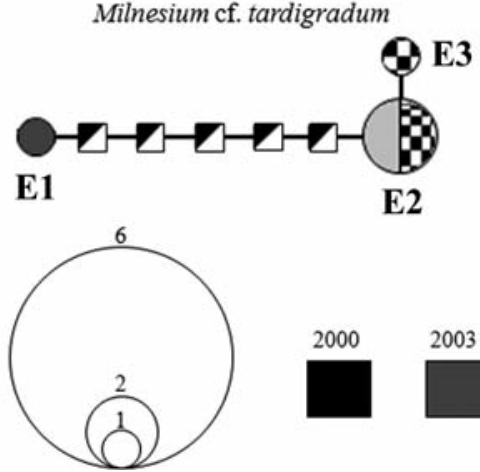

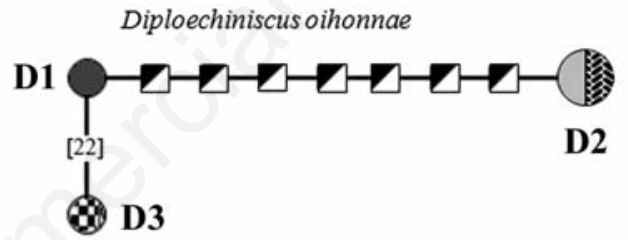

Macrobiotus cf. macrocalix

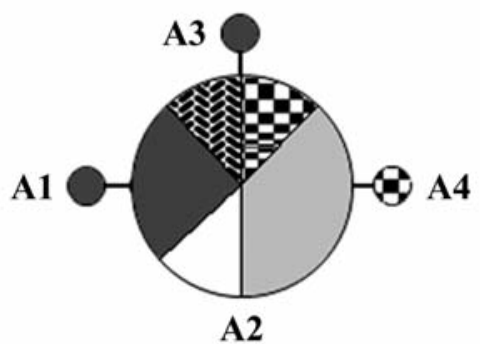

Minibiotus cf. furcatus
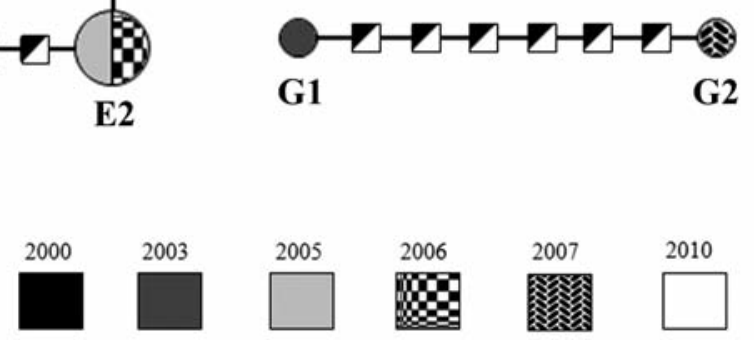

Fig. 3. Minimum spanning network. Haplotypes are represented by circles with the area being proportional to their frequency of occurrence. Lines represent single mutational events, while small half filled squares denote missing/ideal haplotypes. Different shades/patterns denote different sampling years. Letters and numbers indicate haplotypes as in Tab. 3. 
the largest fire. Most species found in the sampling area were recovered from that sample. The pairwise comparisons of Shannon-Wiener indices (Tab. 2) evidence that 2003 sample (just before the big fire) significantly differs from all other samples, with the lone exception of 2005. The difference between 2000 and 2003 samples can be explained by the fire happened in 1998 , followed by a diversity recovery towards the climax. As a further support, we can note that 2000 sample does not differ from all the other samples. As said, 2005 does not statistically differ from 2003, but we should note that 2005 is largely the least abundant sample in specimens (only 17; Tab. 1). There are differences between 2005 and the following samples, but never at the level of $\mathrm{P}<0.001$ as in the comparisons between the latter samples and 2003.

The 2003 pre-fire sample shows the highest species richness and Shannon index, corroborating a moss and lichen successional study conducted in the same area, where post-fire biodiversity levels significantly decreased in burned areas compared with unburned ones, with the differences decreasing over time (Sim-Sim et al., 2004).

The 2003 fire was the probable cause behind the greatest decrease in population richness and clearly delayed recovery. Larger fires destroy a larger forest area than a smaller fire, thus killing more animals as well as their live substrates. Therefore, fewer animals are left alive and at a greater distance, making the process of re-colonisation less likely. This likely causality behind the registered fluctuation in population density is very clearly shown in Fig. 1. Destruction of living substrates affecting invertebrate biodiversity had previously been studied by Diniz et al. (2011) who noted the occurrence of lepidopteran larvae on their host plants was between 2.4 and 5.2 times higher in unburned areas than in burned ones.

The lower number of species found after the fires matches the results of York (1999), who showed that areas subjected to frequent low-intensity fires had significantly lower levels of several macro-invertebrate taxa. York (1998) noted the loss of morphospecies as a consequence of frequent fires reaching $46 \%$ that of control unburned areas.

Most species found before the main fire are also found after it, indicating tardigrades have a high re-colonization capability. The only exceptions are H pallidus and E. quadrispinosus, while only represent $1.09 \%$ of the overall sample. In the last three samples, it is evident that the high specimen numbers result from the presence of a different dominant species each year. A particular result is represented by the 2010 sample, in which there is the highest $\lambda$ and one species, E. blumi, never present before, represents $82 \%$ of the tardigrade population. Microhabitat could be invoked, but in reality the available information cannot help us in explaining this particular situation.

The genetic spanning network shows a reduced num- ber of substitutions among most haplotypes, with the exception of D. oihonnae, where two haplotypes are separated by 22 substitutions. This accounts for a Kimura 2-parameters distance of 4\% (Vicente et al., 2013), still within the single-species limits. Only haplotypes A2, F1 and $\mathrm{H} 1$ are represented both pre- and post-main fire. That means that even though most species were able to return to the destroyed location, almost $90 \%$ of the haplotypes are unique to either one of the situations: pre or post-fire destruction (see also high values of haplotype diversity in all samples; Tab. 3). However, this does not imply a genetic diversity loss as a sole consequence of fire. The haplotypes vary within the same species in the different years after the fire. A good example is Diploechiniscus with a different haplotype in every sampling year, indicating a very dynamic change in population genetic structure. Given the limited data, we cannot exclude that some haplotypes not found in 2000-2003 were already present in those years. We point out that a negative relationship was found between the different success rates in genetic sequencing, from year to year, and corresponding number of sequences obtained. This means that scored genetic richness levels are valid and were not biased by the methodology or by chance.

Nonetheless, the high numbers of newly scored haplotypes led us to hypothesise that at least some of them come from areas where the passive transport is possible. It is evident that the more common haplotypes were able to survive in the same or in nearby non-burned habitats and then re-colonise the original spot as shown by haplotype A2. The fact that all other post-main fire haplotypes besides A2, F1 and $\mathrm{H} 1$ are not only new but also not found consistently, suggests that the original genetic pool was replaced, and that the community will need many years to reach a new balance. Original biodiversity indexes were far from being reached seven years after the main fire and it is not possible to predict when and if they will ever be restored. We should however consider that a longer term study could constitute a very difficult goal. Only $3 \%$ of Australian lowland savannah landscapes has remained unburned for more than 5 years (Andersen et al., 2005).

In our opinion, an implementation of a molecular approach should be considered in the elaboration of future forest and other natural areas management strategies, including fire management as well as biodiversity conservation policy.

We conclude that even though terrestrial tardigrades can re-colonise a given destroyed habitat with considerable ease, significant biodiversity richness is lost in a likely cause and effect relationship to destructive forest fires. The level of biodiversity loss in such an event is, at least in part, determined by the magnitude of the fire. Our data could serve as reference baseline for co-existing meiofauna taxa such as nematodes or rotifers. 


\section{ACKNOWLEDGMENTS}

The authors wish to thank Dr. César Garcia (Botanical Garden, Lisbon) for providing the moss samples used in this study. We would like to thank the three anonymous reviewers, whose comments helped to improve the quality of this manuscript. We are also very grateful to Dr. Juliana Hinton (McNeese State University, USA) and the anonymous reviewers for their kindness in revising English language. This work was partially funded by the Portuguese Fundação para a Ciência e a Tecnologia with a grant (SFRH/BD/39234/2007) to the first author. The research is also part of the project MoDNA supported by Fondazione Cassa di Risparmio di Modena (Italy) and the University of Modena and Reggio Emilia (Modena, Italy).

\section{REFERENCES}

Andersen AL, Cook GD, Corbett LK, Douglas MM, Eager RW, Russell-Smith J, Setterfield SA, Williams RJ, Woinarski JCZ, 2005. Fire frequency and biodiversity conservation in Australian tropical savannas: implications from the Kapalga fire experiment. Austral. Ecol. 30:155-167.

Andersen AL, Müller WJ, 2000. Arthropod responses to experimental fire regimes in an Australian tropical savannah: ordinal-level analysis. Austral. Ecol. 25:199-209.

Andrew N, Rodgerson L, York A, 2000. Frequent fuel-reduction burning: the role of logs and associated leaf litter in the conservation of ant biodiversity. Austral. Ecol. 25:99-107.

Araújo EA, Ribeiro GA, 2005. Fire impacts on the entomofauna of the soil in forest ecosystems. Nat. Desenvolvimento 1:75-85.

Cesari M, Bertolani R, Rebecchi L, Guidetti R, 2009. DNA barcoding in Tardigrada: the first case study on Macrobiotus macrocalix Bertolani and Rebecchi 1993 (Eutardigrada, Macrobiotidae). Mol. Ecol. Resour. 9:699-706.

Cesari M, Giovannini I, Bertolani R, Rebecchi L, 2011. An example of problems associated with DNA barcoding in tardigrades: a novel method for obtaining voucher specimens. Zootaxa 3104:42-51.

Costa L, Thonicke K, Poulder B, Badeck FW, 2011. Sensitivity of Portuguese forest fires to climatic, human, and landscape variables: subnational differences between fire drivers in extreme fire years and decadal averages. Reg. Environ. Change 11:531-551.

Diniz IR, Higgins B, Morais HC, 2011. How do frequent fires in the Cerrado alter the lepidopteran community? Biodivers. Conserv. 20:1415-1426.

Excoffier L, Laval G, Schneider S, 2005. Arlequin ver. 3.0: an integrated software package for population genetics data analysis. Evol. Bioinform. Online 1:47-50.

Folmer O, Black M, Hoeh W, Lutz R. Vrijenhoek R, 1994. DNA primers for amplification of mitochondrial cytochrome $\mathrm{c}$ oxidase subunit I from diverse metazoan invertebrates. Mol. Mar. Biol. Biotechnol. 3:294-299.

Gandhi KJK, Spence JR, Langor, DW, Morgantini LE, 2001. Fire residuals as habitat reserves for epigaeic beetles (Coleoptera: Carabidae and Staphylinidae). Biol. Conserv. 102:131-141.

Instituto de Conservação da Natureza e das Florestas, 2007.
Available from: www.icnf.pt. Accessed: 19 September 2012.

Librado P, Rozas J, 2009. DnaSP v5: A software for comprehensive analysis of DNA polymorphism data. Bioinformatics 25:1451-1452.

Malmström A, Person T, Ahlström K, Gongalsky KB, Bengtsson J, 2009. Dynamics of soil meso- and macrofauna during a 5 -year period after clear-cut burning in a boreal forest. Appl. Soil Ecol. 43:61-74.

McCullough DG, Werner RA, Neumann D, 1998. Fire and insects in northern and boreal forest ecosystems of North America. Annu. Rev. Entomol. 43:107-127.

Millennium Ecosystem Assessment, 2005. Ecosystems and human well-being: biodiversity synthesis. World Resources Institute ed., Washington, DC: 86 pp.

Moretti M, Obrist MK, Duelli P, 2004. Arthropod biodiversity after forest fires: winners and losers in the winter fire regime of the southern Alps. Ecography 27:173-186.

Naveh Z, 1998. From Biodiversity to Holistic conservation of the biological and cultural diversity of Mediterranean landscapes, p. 23-50. In: P. Rundel, G. Montenegro and F.M. Jaksic (eds.), Landscape disturbance and biodiversity in Mediterranean-type ecosystems. Ecological studies. Springer.

New TR, Yen AL, Sands DPA, Greenslade P, Neville PJ, York A, Collet NG, 2010. Planned fires and invertebrate conservation in south east Australia. J. Ins. Conserv. 14:567-574.

Parr CL, Andersen AN, 2006. Patch mosaic burning for biodiversity conservation: a critique of the pyrodiversity paradigm. Conserv. Biol. 20:1610-1619.

Quartau JA, 2009. Preventative fire procedures in Mediterranean woods are destroying their insect biodiversity: a plea to the EU Governments. J. Ins. Conserv. 13:267-270.

Sim-Sim M, Carvalho P, Sérgio C, Garcia C, Rego F, 2004. Recolonisation and changes in bryophyte and lichen biodiversity in burned areas from the Serra da Estrela (Portugal). Cryptogam. Bryol. 25:279-296.

Simorangkir D, 2007. Fire use: is it really the cheaper land preparation method for large-scale plantations? Mitig. Adapt. Strat. Glob. Change 12:147-164.

Tamura K, Peterson D, Peterson N, Stechler G, Nei, M, Kumar S, 2011. MEGA5: molecular evolutionary genetics analysis using maximum likelihood, evolutionary distance, and maximum parsimony methods. Mol. Biol. Evol. 28:2731-2739.

Teacher AGF, Griffiths DJ, 2011. HapStar: automated haplotypes network layout and visualization. Mol. Ecol. Resour. 11:151-153.

Vicente F, 2010. Micro-invertebrates conservation: forgotten biodiversity. Biodivers. Conserv. 19:3629-3634.

Vicente F, Fontoura P, Cesari M, Rebecchi R, Guidetti R, Serrano $A$, Bertolani $R, 2013$. Integrative taxonomy allows the identification of synonymous species and the erection of a new genus of Echiniscidae (Tardigrada, Heterotardigrada). Zootaxa 3613:557-572.

Wallace LL, Crosthwaite KA, 2005. The effect of fire spatial scale on Bison grazing intensity. Landscape Ecol. 20:337349.

Yanovsky VM, Kiselev VV, 1996. Response of the endemic insect fauna to fire damage in forest ecosystems, p. 409-413. In: J.G. Goldammer and V.V Furyaev (eds.), Fire in ecosystems of boreal Eurasia. Kluwer Academic Publishers. 
York A, 1998. Managing for biodiversity: what are the long-term implications of frequent fuel reduction burning for the conservation of forest invertebrates? Proceedings of the Third International Conference on Forest Fire Research, Luso, Portugal.

York A, 1999. Long-term effects of frequent low-intensity burning on the abundance of litter-dwelling invertebrates in coastal blackbutt forests of southeastern Australia. J. Ins. Conserv. 3:191-199.

York A, 2000. Long-term effects of frequent low-intensity burning on ant communities in costal blackbutt forests of southeastern Australia. Austral. Ecol. 25:83-98.

Zar JH, 1996. Biostatistical analysis. $3^{\text {rd }}$ ed. Prentice Hall, Upper Saddle River, NJ, USA: 662 pp. 